\title{
Comparison of the cost for two aspects of health care in hospitals in the state and private sector
}

\author{
K S H de Silva ${ }^{1}$, H Wijesundera ${ }^{1}$, J A A M Dilhani ${ }^{1}$, H D P Premarathne ${ }^{1}$, N S Gunawardena ${ }^{2}$ \\ Journal of the Ceylon College of Physicians, 2012, 43, 24-27
}

\begin{abstract}
Introduction: Every child in Sri Lanka is entitled to free health care in state hospitals. Nevertheless, there is a cost involved with hospitalization which is borne by the parents.
\end{abstract}

\section{Objectives:}

- To estimate the cost incurred for drugs and investigations by the parents of a child hospitalized in a state sector hospital.

- To compare the total cost for drugs and investigations if the same management had been done in a hospital in the private sector.

Method: From October 2010, 500 children admitted to a ward at the Lady Ridgeway Hospital (LRH), Colombo were selected by systematic sampling for the study. Patients discharged before 24 hours were excluded. The duration of hospitalization was categorized as $\leq 3$ days, 4-7 days, 8-14 days and $>2$ weeks.

The expenditure borne by the parents for the occasional drugs purchased and for investigations requested from the private sector was recorded. This was then compared with the total cost for all the drugs given and investigations done if their children were hospitalized for the same illness and duration in a private sector hospital.

Results: There were 311 (62\%) boys and 189 girls. Mean age was 3.5 years. Monthly family income ranged from Rs 2000.00 to Rs $210,000.00 .51 \%$ were hospitalized for $\leq 3$ days. The average cost in the private sector for drugs and investigations was significantly greater than the cost incurred by the parents at LRH.

\footnotetext{
${ }^{1}$ Department of Paediatrics, Faculty of Medicine, University of Colombo.

${ }^{2}$ Department of Community Medicine, Faculty of Medicine, University of Colombo.
}

Conclusion: Cost incurred for drugs and investigations is significantly less for parents of a sick child in a state hospital.

Key words: Health care cost, children, state and private sector hospitals.

\section{Introduction}

Every child in Sri Lanka is entitled to free health care in state sector hospitals. Nevertheless, there is a cost involved even with hospitalization in such an institution that is borne by the parents. This is for the occasional investigation or a drug that needs to be purchased when not available in the hospital and at times parents have been known to be critical of this. But nothing is free if a child is admitted to a hospital in the private sector. The choice regarding the place of admission is mostly the parents'. This study was done to document the cost of two aspects of health care in the state and private sector.

\section{Objectives}

- To estimate the cost incurred for drugs and investigations borne by the parents of a child hospitalized in a state sector hospital.

- To compare the total cost for drugs and investigations if the same management had been done in a hospital in the private sector.

\section{Method}

From October 2010, 500 children admitted to the University Paediatric Unit at Lady Ridgeway Hospital (LRH), Colombo were selected by systematic sampling for the study. Patients discharged before 24 hours were not included. The bystanders were given an information sheet regarding the study and verbal consent was obtained. An interviewer administered questionnaire was used to document the socio-demographic data.

The duration of hospitalization was categorized as 3 days, 4-7 days, 8-14 days and $>2$ weeks and the investigations done, medications given and procedures carried out during their hospital stay were recorded. 
We estimated the cost of drugs the parents had to purchase and the prices of any investigations requested from the private sector during their stay at $\mathrm{LRH}$. This expenditure borne by the parents was then compared with the total cost for all the drugs given and investigations done if their children were hospitalized for the same illness and duration in a private sector hospital.

To estimate the cost of the investigations when done from the private sector, we used the average values from the publicly quoted prices for these items from $\leq 3$ such leading hospitals in Colombo. The cost of the generic and branded drugs was taken from the price list published by the State Pharmaceutical Corporation in 2009.

Ethical review committees of the Faculty of Medicine, Colombo and LRH gave permission for the study.

\section{Results}

There were 311 (62\%) boys and 189 girls. Their ages ranged from 2 weeks to 12 years with a mean age of 3.5 years. Monthly family income ranged from Rs 2000.00 to Rs $210,000.00$. The duration of the patients' hospital stay is given in Table 1 . Majority (256, $51 \%$ ) were hospitalized for $\leq 3$ days and 22 children $(4.4 \%)$ for $>2$ weeks. The mothers'education level is given in Table 2 and Table 3 is a summary of the duration of hospital stay with the monthly family income.

Tables $4 \mathrm{a}$ and $4 \mathrm{~b}$ are a comparison of the average expenditure borne by the parents with children in the state sector hospital, for the occasionally purchased drugs and investigations done from outside, and the average of the total cost for drugs and investigations if these patients were hospitalized in the private sector for the same illness and duration of hospitalization.

The expenditure the parents would have incurred in the private sector was significantly greater than in the state sector.

Table 1. Duration of hospitalization

\begin{tabular}{cc}
\hline Duration (days) & Number of patients (\%) \\
\hline$\leq 3$ & $256(51.2)$ \\
$4-7$ & $164(32.8)$ \\
$8-14$ & $58(11.6)$ \\
$>14$ & $22(4.4)$ \\
\hline
\end{tabular}

Table 2. Mothers' education level $(n=450)$

\begin{tabular}{lc}
\hline Education level & Number of mothers \\
\hline Never been to school & 5 \\
Grade 1 - 5 & 9 \\
Grade 5 - O'Level & 336 \\
O'Level - A'Level & 87 \\
Tertiary education & 13 \\
\hline
\end{tabular}

Table 3. Monthly income and duration of hospitalization $(n=490)$

\begin{tabular}{|c|c|c|c|c|}
\hline \multirow[t]{2}{*}{ Income (Rs) } & \multicolumn{4}{|c|}{ Duration of hospitalization (days) } \\
\hline & $\leq 3$ & $4-7$ & $8-14$ & $>14$ \\
\hline$<5000.00$ & 2 & 6 & - & 1 \\
\hline $5,000-10,000.00$ & 15 & 17 & 6 & 5 \\
\hline $10,000-20,000.00$ & 83 & 63 & 22 & 8 \\
\hline$>20,000.00$ & 154 & 73 & 28 & 7 \\
\hline
\end{tabular}


Table 4a. Comparison of the cost for drugs in the state and private sector

\begin{tabular}{|c|c|c|c|c|c|}
\hline \multirow{2}{*}{$\begin{array}{l}\text { Duration of } \\
\text { hospital } \\
\text { stay (days) }\end{array}$} & \multicolumn{2}{|c|}{$\begin{array}{c}\text { Total cost for drugs } \\
\text { Rs }\end{array}$} & \multicolumn{2}{|c|}{$\begin{array}{c}\text { Average cost for drugs } \\
\text { (SD) Rs }\end{array}$} & \multirow[t]{2}{*}{$\begin{array}{l}\text { Statistical } \\
\text { significance }\end{array}$} \\
\hline & State sector & Private sector & State sector & Private sector & \\
\hline$\leq 3$ & 4754.00 & 33023.21 & $18.57(52.86)$ & $132.62(581.84)$ & $S N D=4.36 p<0.001$ \\
\hline $4-7$ & 2870.00 & 158671.55 & $17.50(70.54)$ & 985.54 (3564.14) & $S N D=60.9 p<0.001$ \\
\hline $8-14$ & 2280.00 & 90103.46 & $39.31(92.24)$ & 1580.76 (1968.61) & SND $=175 \quad p<0.001$ \\
\hline$>14$ & 100.00 & 147187.39 & 4.54 (21.32) & 7008.92 (21942.39) & SND $=7.13 p<0.001$ \\
\hline
\end{tabular}

Table 4b. Comparison of the cost for investigations in the state and private sector

\begin{tabular}{|c|c|c|c|c|c|}
\hline \multirow{2}{*}{$\begin{array}{l}\text { Duration } \\
\text { of hospital } \\
\text { stay } \\
\text { (days) }\end{array}$} & \multicolumn{2}{|c|}{$\begin{array}{c}\text { Total cost for investigations } \\
\text { Rs }\end{array}$} & \multicolumn{2}{|c|}{$\begin{array}{c}\text { Average cost for investigations } \\
(S D) \text { Rs }\end{array}$} & \multirow[t]{2}{*}{$\begin{array}{l}\text { Statistical } \\
\text { significance }\end{array}$} \\
\hline & State sector & Private sector & State sector & Private sector & \\
\hline$\leq 3$ & 14814.00 & 541524.00 & 57.87 (308.08) & 2115.33 (2836.36) & $\begin{array}{l}\text { SND }=16.13 \\
p<0.001\end{array}$ \\
\hline $4-7$ & 35510.00 & 481249.00 & 217.85 (1736.42) & 2934.45 (3232.71) & $\begin{array}{l}\text { SND }=16.56 \\
p<0.001\end{array}$ \\
\hline $8-14$ & 24780.00 & 324706.00 & 427.24 (1331.87) & 5598.38 (4382.54) & $\begin{array}{l}\text { SND }=25.36 \\
p<0.001\end{array}$ \\
\hline$>14$ & 21875.00 & 152282.00 & 994.32 (2328.68) & 6921.90 (5001.05) & $\begin{array}{l}\text { SND }=24.01 \\
p<0.001\end{array}$ \\
\hline
\end{tabular}

\section{Discussion}

The results of this study are not surprising. Although only 2 aspects were studied the difference in expenditure is enormous. If all other expenses were to be analysed such as room charges, special investigations, consumables, doctors' fees to name just a few, the difference in cost would have been exorbitant. Certain special investigations done while at $\mathrm{LRH}$, at no cost to the parents, are worthy of mention -32 children had neuro-imaging in the form of CT scans
(16) and MRI scans (16) and 22 had EEGs performed. It is not only the economically disadvantaged who seek treatment in the state sector. Five families had a monthly income greater than Rs. 100,000/- and the income was over Rs. 50,000/- in 15 families.

Apart from some expenditure borne by the parents which is negligible when compared to the cost in the private sector, state-of-the-art care is available and accessible in state sector hospitals to everyone in the 
country. But overcrowding, lack of privacy and lack of facilities for the mothers ${ }^{1}$ are aspects which need to be addressed and improved in the state hospitals which are also important for the well being of a sick child.

A close relationship exists between illness, health expenditure and poverty2,3,4. A study involving 11 lowmiddle income countries in Asia $^{2}$ demonstrated the effect of out-of-pocket payments for health care as exacerbating poverty. They reported a $14 \%$ increase than conventional estimates in the overall prevalence of absolute poverty when out-of-pocket payments to finance health care were considered.

In Sri Lanka the cost of hospitalization in the state sector is borne by the government. The largest part of health spending is for inpatient and outpatient care (curative care) as opposed to prevention and public health services ${ }^{5}$. This expenditure had increased to $52 \%$ of the total health expenditure (THE) in 2008 compared to $46 \%$ in $1990^{5}$. This policy facilitates the process of ensuring equity of health care for hospitalized patients in the state sector hospitals, irrespective of the socio-economic status of patients.

\section{Conclusions}

Parents have a choice when their sick children need hospitalization to obtain care in a hospital in either the state sector or private sector. It is thus reassuring to note that optimal and comparable care is available in state sector hospitals at minimal cost to the parents.

\section{References}

1. de Silva S, Dharmage S. Plight of mothers in a paediatric ward. Proceedings of the 30th Annual Scientific Congress of the Sri Lanka Paediatric Association, May 1995.

2 van Doorslaer Eddy, O'Donnell Owen, Rannan-Eliya Ravi P, et al. Effect of payments for health care on poverty estimates in 11 countries in Asia: an analysis of household survey data. Lancet 2006; 368: 1357-64.

3 Jayasinghe Saroj. Poverty, inequality and health: issues relevant to South Asia. Ceylon Medical Journal 2005; 50(2): 80-3.

4 Cirto C, Michael R. Measuring poverty: A new approach. Washington DC: National Academy Press, 1995.

5 Sri Lanka Health Accounts. National Health Expenditure 1990-2008. IHP Health Expenditure Series No 2. 